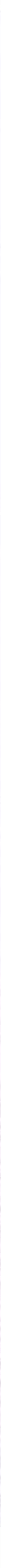




\section{Tópicos sobre Arte Popular: 40 años del Premio a López Antay}

Alfonso Castrillón Vizcarra

Instituto de Investigaciones Museológicas y Artísticas de la Universidad Ricardo Palma

El presente artículo presenta los puntos más destacados de la polémica suscitada con motivo del otorgamiento del Premio Nacional de Cultura al artista popular Joaquín López Antay en el año 1976. Luego de una introducción en que se da cuenta de los hechos, la conformación del jurado y la reacción de los artistas académicos, el autor fundamenta su tesis sobre la diferencia entre arte popular y artesanía examinando las propuestas de otros estudiosos que salieron a la luz en los años que vinieron. El autor concluye proponiendo la denominación de arte popular para significar hoy día aquellas manifestaciones que no son "arte informado" y tampoco artesanía.

Palabras clave: López Antay, Premio Nacional de Cultura, arte, arte popular, artesanía, arte informado.

This article presents the most prominent points of the controversy brought on by the giving of the National Culture Prize to the popular artist Joaquín López Antay in 1976. After an introduction, in which the facts of the situation are explained and a description of the composition of the award panel and the reaction of the academic artists is given, the author bases their thesis on the difference between popular art and professional craftsmanship, examining the proposals of other scholars that came to light in the years they came out.

The author concludes by proposing the naming of popular art to mean today those manifestations that are neither informed art nor works of professional craftsmanship.

Key words: López Antay, Culture National Prize, art, folk art, craftsmanship, academic art.

\section{Introducción.}

El presente texto pretende tomar algunos temas desarrollados en trabajos míos sobre arte popular entre los años 1976 y 1977, y someterlos a una relectura después de las cuatro décadas transcurridas desde que se acordó otorgar el Premio Nacional de Cultura a Joaquín López Antay y la polémica que siguió entonces. Han pasado muchos años y mientras tanto la teoría artística ha ampliado sus horizontes, haciendo más comprensible aquello que en los setenta, aquí, parecía inaceptable ${ }^{1}$.

1 El paso de la modernidad a la posmodernidad. En Europa y Estados Unidos la secuencia puede ser ilustrada como sigue: Abandono de las normas académicas del 900; surgimiento de las vanguardias europeas hasta Duchamp; Expresionismo abstracto norteamericano; las nuevas vanguardias en USA: del Pop al arte conceptual. 
Se puede decir que la preocupación por el arte popular peruano comienza en la década del 20 con los artículos de José Sabogal. ${ }^{2}$ Le siguen José María Arguedas y Emilio Mendizábal ${ }^{3}$ que dedicaron algunos trabajos al Sanmarkos o retablo, partiendo de la descripción y la explicación vivencial, usando indistintamente las denominaciones de "arte popular" o "arte tradicional". Lo que hicieron estos investigadores se fundaba en la realidad encontrada en los Andes entre los años 40 y 50, siguiendo un método más cercano a la antropología que a la historia del arte.

La relectura aquí propuesta pone énfasis en ese lapso preciso donde el arte popular pasa de la total ignorancia para la clase dominante al progresivo conocimiento de su naturaleza y sus cambios, demostrando su existencia como un proceso donde la "tradición" también avanza, a ritmo más lento que la modernidad, pero camina impulsada por el impacto de los medios de comunicación y la economía. ¿Por qué esta demarcación? Porque nos permite estudiar la producción antes y después de las influencias, su ingreso al mercado capitalino, y por fin, su incorporación a la historia del arte peruano y a la musealización. El otorgamiento del premio a López Antay y la consecuente polémica se inscriben pues en una época histórica dada y se basan en hechos relacionados con la producción de objetos artísticos, su distribución y aceptación por una clase social y no sobre especulaciones separadas de los objetos y de las relaciones sociales que le dan sentido. Denomino arte popular a las creaciones de este período.

\section{1.- Los hechos.}

En 1975 fui invitado por el Instituto Nacional de Cultura (INC) para conformar la comisión que debía discernir el Premio Nacional de Cultura, instituido por el Estado para los intelectuales y artistas cada dos años. El jurado para la sección arte estaba compuesto por Cristina Gálvez, Carlos Bernasconi, Juan Gunther, Leslie Lee, Vera Stastny, Enrique Pinilla y quien escribe; recuerdo que en las primeras reuniones se barajaron algunos nombres conocidos y meritorios. Yo llevaba la propuesta del pintor Carlos Quizpez Asín, pero cambié de opinión ante la idea de Leslie Lee de postular el nombre del artista popular Joaquín López Antay. Los argumentos resultaban contundentes: el largo ejercicio de una vida dedicada al arte de su pueblo, el enriquecimiento del lenguaje plástico de un objeto adoptado como el retablo, la pervivencia de las costumbres, ritos y cosmovisión del mundo andino, todos valores genuinos y equiparables a manifestaciones artísticas en cualquier parte del mundo. Estas razones y la letra del reglamento, que ese año no hacía ninguna distinción entre arte y artesanía, dejaba la libertad de premiar por primera vez a un artista popular. Y así fue. La nominación de López Antay en aquel diciembre de 1975 causó gran revuelo y abrió una acalorada polémica con los artistas "informados" ${ }^{4}$, quienes protestaron airadamente aduciendo que no se podía dar el Premio Nacional a un artesano; además, decían, la obra de López Antay no era arte sino artesanía. Tanto hirió el premio su amor propio que se juntaron en una asociación, la Asociación Profesional de Artistas Plásticos (Aspap), para tener más fuerza y combatir la decisión del jurado. Siempre individualistas y desinteresados por el quehacer político y social, se juntaron, sin embargo, cuando su mundo de la producción se vio amenazado por "otro tipo" de arte. Creyeron juntar para sus fines a todos los artistas plásticos del Perú, pero no fue así, pronto un nutrido grupo de disidentes se manifestó con una nota fechada el 7 de enero

2 José sabogal publica “Los mates y el yaraví” en Amauta, Lima, №26 (Setiembre-Octubre de 1929): 17-20.

3 Arguedas, José María. El arte popular religioso y la cultura mestiza. Sobretiro de la Revista del Museo Nacional, Tomo XXVII, Lima, (1951) 1958; Mendizábal Losack, Emilio, Del Sanmarkos al retablo ayacuchano, dos ensayos pioneros sobre arte tradicional peruano, Universidad Ricardo Palma-ICPNA, Lima 2003. El libro-catálogo que acompañó la exposición realizada en el ICPNA de Miraflores, contiene dos artículos de Mendizábal: "Una contribución al estudio del arte tradicional peruano" y "La difusión, aculturación y reinterpretación a través de las cajas de imaginero ayacuchanas". (1958).

4 Como lo he dicho en otras oportunidades prefiero llamarlos "informados" y no "cultos", cuya contraparte sugiere que quienes no han hecho la academia sean incultos. 
de 1976, en la que declaraban no estar de acuerdo con el comunicado de la Aspap, cuyos directivos habían obrado sin consultar con las bases. Este atropello fue la causa de la creación del Sindicato Único de Trabajadores en las Artes Plásticas, constituido por disidentes ${ }^{5}$ de la Aspap. Así, la mala práctica de sus dirigentes y la ignorancia demostrada sobre nuestro arte popular mestizo, dio lugar a un frente que puso a su institución entre dos fuegos.

Desde el bastión de la producción, la Escuela Nacional de Bellas Artes (ENBA) y sus profesores, como era de esperar, saltaron a la palestra y se esmeraron en buscar argumentos para traerse abajo la decisión del jurado. Dentro de las muchas declaraciones que se hicieron en los diarios destaca esta perla: "El artesano expresa la mitología elemental de la masa indiferenciada: el artista expresa el mensaje recogido de lo hondo del alma humana, como valor absoluto en sí”. Como puede verse, esta declaración que discrimina al artista popular dándole el apelativo de "artesano" y lo descalifica por no expresar "lo hondo del alma humana" es clamorosamente absurda.

En los primeros días de enero de 1976, la Aspap hizo llegar a los medios el comunicado titulado "La Aspap Cuestiona Premio Nacional De Cultura Otorgado Para Las Artes" , donde, con malicia estudiada, se argumentaba que si con el premio se hubiese querido "consagrar la labor de un artesano, que merece nuestro respeto y simpatía más sinceros, habría motivado, ciertamente, nuestro mayor beneplácito, de haberse producido dentro del marco de un premio específicamente destinado a la artesanía. Pero el fallo que impugnamos adquiere un sentido totalmente diferente e inaceptable, el sentar la tesis para nuestro proceso cultural de una significación mayor que la pintura o la música." (Las cursivas son nuestras)

El comunicado sigue esgrimiendo argumentos absurdos, como considerar al retablo una expresión meramente artesanal "que no logra superar su primigenia inspiración colonial"8. La desafortunada declaración significa que quienes suscribieron el comunicado no se detuvieron en analizar los retablos de López Antay, donde éstos han sufrido una transformación evidente muy lejos del retablo barroco de donde se inspira y cuyos contenidos (creencias religiosas, celebraciones agrarias) son fruto de un mestizaje y adquieren por eso su indiscutible originalidad.

Los redactores del comunicado agregaron que los "pintorescos retablos" satisfacen el ansia de exotismo del turista extranjero "y en el caso de nuestro turismo interno, las ansias mezcladas de populismo que caracterizan la mentalidad de ciertas capas, por lo visto siempre dominantes, de nuestra burguesía teñida de progresismo intelectual e inmersa en irremediables complejos de culpa." "Esta última apreciación es injusta pues al mercado (tanto turístico como no turístico; externo como interno) no sólo le interesa el arte popular sino también el arte informado; el mercado está abierto a todos los gustos y mal se puede decir que sólo interesa a ciertas capas, como a la burguesía cargada de "complejos de culpa".

Si bien es cierto que la polémica se desata en el seno de la burguesía ilustrada sin la participación o descargo de los artistas populares, no se puede hablar, sin embargo, de conciencia de clase, sino de un desacuerdo entre dos sectores de la misma clase, unos conservadores y otros progresistas. ${ }^{10}$

5 Los disidentes: Sindicato Único de Trabajadores en las Artes Plásticas: Entre los firmantes del pronunciamiento se encontraban: Sabino Springett, Ugo Camandona, Tilsa Tsuchiya, Ciro palacios, Félix Oliva, Martha Vértiz, Gastón Garreaud, Ernesto Zamalloa,Teresa Brown, Etna Velarde, Mario Piacenza, entre otros.

6 Ugarte, 1976.

7 “Aspap critica premio a Joaquín López A.”. Diario La Crónica, martes 6 de enero de 1976: p 15.

8 Ibid., pp15.

9 Ibid., pp15.

10 Castrillón: 2001: 146, nota № 3 . 
Ante esta situación se debía centrar la discusión en la diferenciación entre arte y artesanía, para luego volver a López Antay y encontrar una razón que justifique el premio y el título de artista popular, y a eso me aboqué en los años siguientes ${ }^{11}$.

\section{2.- ¿Artesanía o arte popular? Desbrozar el camino.}

Iniciada la polémica inmediatamente luego de la dación del premio, nos dimos cuenta de que en el ambiente de los artistas informados existía una gran desinformación sobre las artes populares y en general se diferenciaba claramente entre una producción de obras aceptadas por las academias y los museos denominadas "las artes" y otras que no lo eran, siendo nombradas genéricamente como artesanías. Antes del premio, esta diferenciación era imperceptible y no constituía una categoría opuesta a otra, en este caso al arte informado: el arte popular no "existía" para la cultura peruana, aunque ya los trabajos de Arguedas y Mendizábal habían dado cuenta de su naturaleza.

Convencido de los valores plásticos y el contenido cultural de las obras de López Antay, llegué a la conclusión de que en el imaginario público, el concepto artesanía abarcaba muchos objetos, sin embargo, diferenciados netamente no solo por la factura, sino por la intencionalidad; es decir unos eran simples adornos u objetos utilitarios y otros, por la función y el contenido, trascendían hacia significados más complejos, como por ejemplo los Sanmarkos o retablos. En ese entonces era más sencillo meter todo en un mismo saco.

Era necesario, pues, hacer la diferenciación entre arte y artesanía, considerada por algunos fútil; sin embargo, sirvió a la larga para ubicar los trabajos de López Antay y otros maestros dentro de la categoría de "arte popular". La obra del maestro ayacuchano era arte, como expresión de una individualidad que interpretaba a su comunidad, el mundo andino mestizo y merecía estar en el mismo nivel de las creaciones informadas ${ }^{12}$. El artista popular fue abandonando el anonimato y entrando en un mercado que excedía la provincia. Él también era capaz de expresar "lo hondo del alma humana"13 como presumían los artistas informados. Nunca antes se había incluido en la historia del arte peruano un capítulo dedicado al arte popular. Desde el principio sabíamos que no podíamos juzgar una obra de arte popular con los códigos del arte informado: el arte popular tenía los suyos propios. Esta premisa dio como resultado estudios posteriores ${ }^{14}$ dedicados a destacar los valores formales, la continuidad cultural y las características de los objetos por sus tipologías ${ }^{15}$. Se abrió pues el gran momento del arte popular pero también, consecuentemente, el proceso de cambio como era de esperar, porque en el campo de la cultura nada está quieto y todo fluye como las aguas de un río.

El arte popular, gracias a las influencias, al mercado y al museo, fue perdiendo su insularidad provinciana e ingresa al circuito capitalino, pierde su inocencia, su significado religioso y mítico para convertirse en un arte que ha dejado sus primeras características para asumir otras que le da el mercado. En este sentido, paradójicamente, el arte popular como el arte informado se equiparan al convertirse los dos en adorno en las casas limeñas. El único sitio donde los dos se redimen de esta carga es dentro del museo donde son protagonistas y no adornos.

11 Publiqué entonces "Para una teoría del arte popular", La Prensa, Lima, 31 de enero de 1976; “¿Arte popular o artesanía”, Historia y Cultura no 10, Revista del Museo Nacional de Historia, Lima, marzo de 1977; "Arte popular e ideología estética” En Preliminares, Instituto de Investigaciones Humanísticas, UNMSM. Sin fecha, (ca. 1977). En: Castrillón Vizcarra, Alfonso. “¿El ojo de la navaja o el filo de la tormenta?”, Editorial Universitaria Ricardo Palma, Lima, 2001.

12 El arte popular también está cargado de información que, sin embargo, la Academia no sabe leer e interpretar y sí comprenden los habitantes del ande.

13 Ugarte Eléspuru, Juan Manuel, Suplemento dominical de El Comercio 4 de enero de 1976.

14 Stastny, 1980.

15 Stastny, Francisco, 1979. 


\section{3.- La propuesta filosófica.}

Pasada la tormenta del Premio, comenzó un serio interés académico por los problemas de fondo del arte popular. Uno de los primeros en dar a conocer su opinión fue el doctor Edgardo Albizu ${ }^{16}$, filósofo argentino, profesor en esa época de la Universidad Católica del Perú, quien abordó el tema del arte popular desde la filosofía, pero utilizando una vieja palabra creada por los antropólogos del siglo XIX, transida de innumerables significados: folklore. Esta palabra, como artesanía, reúne indistintamente al arte del pueblo, al arte popular, al arte tradicional, confundiendo el panorama antes que aclararlo. Definir es acercarse a una determinada realidad en las circunstancias actuales que nos ha tocado vivir. Estar en el mundo es un continuo redefinirse, hoy más que nunca, dada la dinámica de las comunicaciones electrónicas. Por otro lado, vamos hacia una continua simplificación de las maneras retóricas del siglo XIX. El nuevo carácter de una definición no es cómo queremos que sean las cosas, sino cómo aparecen ellas en la realidad estudiada.

Un punto no compartido con el Dr. Albizu es su opinión sobre "cierta soltura estructural" de las obras de arte popular, donde "la trabazón de sus elementos no parece tan rigurosa como en las llamadas obras cultas"17. Interpretamos aquí "soltura estructural" como flojedad, falla, obra frustrada, que no sólo puede darse en una obra de arte popular sino también en una obra de arte informado ${ }^{18}$. Esta opinión nos hace pensar que el arte popular se ha querido definir siempre con los parámetros de la obra informada y no desde sus propios valores. En mi opinión, acercarse al arte popular desde la filosofía tradicional idealista es lo menos recomendable para un material en proceso de cambio.

\section{4.- La dimensión histórica del arte popular.}

Hasta la aparición de los trabajos de Francisco Stastny, la oposición sostenida por la ASPAP seguía creyendo que la imitación del arte europeo era una nota de distinción que les permitía entrar al selecto grupo de la modernidad. Los textos del profesor sanmarquino, aparecidos entre 1979 y 1981, vinieron a descuadrar el enfoque equivocado de los artistas informados y a proponer otra mirada, las raíces históricas del arte popular peruano, tanto prehispánicas como virreinales.

Stastny, desde su primer texto en $1979^{19}$, da al arte de los pueblos andinos el nombre de arte popular y no artesanía, y afirma que sus objetos "encierran una larga historia para quien sabe interpretarla" ${ }^{20}$. En adelante se esfuerza en demostrar la continuidad cultural desde la lejana historia precolombina, apoyándose en los trabajos de Georges Kubler, John H. Rowe, Bernard Mishkin y Erwin Panofsky, entre otros. De este último, toma el término disyunción, útil para explicar la sobrevivencia disimulada de elementos paganos en el arte popular peruano. Concluye Stastny: "Por donde se mire el arte popular campesino peruano está profundamente ligado a los orígenes culturales prehispánicos" ${ }^{21}$. Pero no solo el arte popular esconde los contenidos paganos de ciertas formas, sino que ciertos artefactos autóctonos "para lograr sobrevivir en un contexto cultural hostil asumen una forma occidental falsa contraria a su verdadera función" 22 , como por ejemplo los tupus que asumen la forma engañosa

16 Edgardo Albizu "Dialéctica del arte popular" Manuscrito. Trabajo leído en el Simposio sobre Arte Popular, INC, 1977. Fue editado más tarde con otras obras bajo el título "Verdades del arte", Universidad Nacional de General San Martín, Buenos Aires, Argentina, año 2000.

17 Albizú, 2000: p. 403.

18 Castrillón Vizcarra, Alfonso, "Arte popular e ideología estética", en ¿El ojo de la navaja o el filo de la tormenta?, Lima, 2001.

19 Stastny. "Dimensión histórica del Arte Popular", 1979.

20 Ibid,. pp. 1.

21 Ibid,. pp.10.

22 Ibid,. pp. 7 
de una cuchara. Para Stastny "la herencia virreinal del arte popular es tan importante como la prehispánica” y por eso no puede soslayarse su "dimensión temporal” y su resonancia histórica "que no sólo es extensa por su antiguiedad, sino que es profunda por la realidad social e histórica compleja que reflejan sus obras". ${ }^{23}$ Juicios certeros de un historiador del arte frente a las críticas infundadas de los artistas informados sobre el valor de las obras de López Antay.

En un segundo texto, Stastny aborda, entre otros argumentos, el tema de la definición del arte popular como "todo lo que no pertenece a las artes oficiales de la Iglesia y de las élites políticas y sociales de los grandes centros urbanos" ${ }^{24}$; pero dentro de este conjunto indiferenciado advierte que no son los productores quienes determinan si un objeto es o no arte popular, sino los usuarios. De esta manera Stastny no ha tenido en cuenta las innovaciones personales o sugeridas y el camino paulatino hacia formas cultas provenientes sin duda de la voluntad del creador en el momento de la producción; por otro lado, tampoco la intervención del distribuidor, llámense arrieros de Carmenca o dueños de boutiques. Los usuarios muestran su preferencia por ciertos temas, formas y colores, pero también adhieren a una determinada ideología (nacionalismo, tradicionalismo); son la última instancia de la cadena y mal pueden determinar si es popular o no. Los objetos culturales llamados arte popular, son el resultado de tres instancias determinadas por su carácter: la producción, distribución y consumo, de acuerdo al ya clásico esquema utilizado por Acha, Canclíni y Lauer.

La variedad del arte popular, lleva a Statsny a proponer cuatro categorías: 1) "objetos artesanales creados en el siglo pasado para las clases medias y acomodadas provincianas; 2) creaciones plásticas empleadas por el campesinado; 3) objetos artísticos de los grupos nativos de la Amazonía; y 4) las artesanías populares manufacturadas para la nueva demanda urbana y turística internacional".

En la primera categoría, el artista trabaja para un grupo social diferente al suyo, las "clases medias y acomodadas provinciales"; en la segunda, para el campesinado, como por ejemplo los Sanmarkos o retablos y otros objetos para uso ritual y ceremonial, a los que Stastny llama arte popular.

La tercera, considera a los "objetos artísticos de los grupos nativos de la Amazonía” y en este caso por la lejanía de estos grupos, sus manifestaciones anónimas y no especializadas. Queda sin sustento la idea de que, como productores y usuarios, determinan la naturaleza de sus objetos, si son o no arte popular. Constituyen una excepción: sus prototipos, originales respecto a los andinos, no han sido pensados para un "mercado" extra étnico, pero el hecho de no tenerlo no los invalida como objetos de arte. Tampoco el hecho de haberlos clasificado como objetos etnográficos.

La cuarta, agrupa las artesanías propiamente dichas para la demanda urbana y turística; Stastny, implícitamente, ha aceptado la diferencia entre arte popular y artesanía, y es consciente de que cuando las artes populares dejan de significar los contenidos originales, religiosos, mágicos o sociales, pierden su “aura"25, se comercializan como adornos. Así pues, la denominación arte popular, como hemos dicho líneas arriba, es una convención creada por la crítica y la historia del arte y no por los usuarios.

En 1981, Edubanco publica Las artes populares del Perú, libro en que Stastny reúne los artículos comentados líneas arriba y otros como "Arte popular y arte de élite", donde afirma que no existe un lenguaje universal en el arte. "La riqueza de los fenómenos humanos es demasiado

23 Ibid,. pp. 12,13.

24 Stastny, "Arte Popular en el Perú: ¿de qué se trata?, en La Revista, № 1/ marzo 1980, p. 42.

25 Benjamin, Walter, 1966: p 24. 
amplia para ser sintetizada en formas simplistas" ${ }^{26}$. La variación y diferencias deben tomarse en cuenta para entender la magnitud de las expresiones artísticas de distintas latitudes y confirma la existencia de una manera de pensar científica y otra "silvestre" o primitiva.

Después de la polémica, el libro de Stastny vino a llenar un gran vacío, ya que hasta el momento no había llegado al gran público una explicación bien fundamentada sobre las características y las virtudes del arte popular peruano, sus raíces culturales y su transformación a lo largo de los años.

\section{5.- "Crítica de la artesanía" Mirko Lauer: los aportes a la teoría marxista del arte.}

En 1982, Mirko Lauer publicó su esperado libro Crítica de la artesanía. Dada la complejidad de esta obra y los límites fijados en este trabajo, conviene comentar sólo algunos aspectos ya evidentes desde su introducción, donde el autor explica el sentido y la metodología que va a seguir, es decir, la teoría social del arte, aplicada al arte tradicional andino, calificado por el autor como "artesanía".

La metodología utilizada por Lauer tiene que ver con la teoría social de impronta marxista, que toma en cuenta "no la apariencia física del objeto, sino las determinaciones de su existencia social como producción-distribución-consumo" 27 . Este pensamiento y los aportes de Acha y García Canclíni, es nuevo en el ámbito latinoamericano si se lo compara con el tradicional europeo. Por ejemplo, la opinión de Corrado Maltese, para el que los objetos artísticos son "formas que implican en cuanto producto una clara separación de la actividad que los ha generado" 28 . Es decir, la obra de arte independiente de cómo se hizo, cómo circula en la sociedad y para quién fue hecha. Esta concepción aísla lo plástico de su contexto histórico social, y según Lauer, está hoy desprestigiada.

Se debe partir del examen del concepto de "arte", que no es una categoría universal, como ha pretendido la estética idealista. Se trata "de una creación cultural de clase y por lo tanto de un fenómeno histórico determinado, con una génesis histórica y llamado a sufrir modificaciones a partir de las evoluciones de la sociedad" 29 .

Puestas las bases metodológicas, Lauer desarrolla sus hipótesis relacionadas con la manera cómo se producen, distribuyen y consumen las "artesanías", nombre puesto por el autor a lo que nosotros llamamos arte popular o arte tradicional. ¿Por qué artesanía y no arte popular? Sospecho que la respuesta de Lauer es que para el efecto es indiferente usar artesanía, arte tradicional o arte popular. Sin embargo, a nuestro entender, al haber escogido “artesanía”, dejó de lado un hecho importante para la polémica del 76. Me explico.

El término artesanía fue el que usó el grupo de artistas informados de la Aspap, que en sus declaraciones y manifiestos, usó la palabra con la intensión de diferenciar un arte menor, hecho por campesinos, del arte académico o informado. De la lectura de los textos disidentes se desprende, no solo una diferenciación formal o de estilo, sino un marcado clasismo: el arte popular no podía acceder al mundo del arte, ni tampoco competir, en un certamen nacional y en la misma categoría, con un artista informado. Como se ve, desde la época de la polémica ha habido una confusión en el uso de los términos y una terca ceguera de los miembros de la Aspap al no admitir los valores plásticos y ancestrales del arte campesino. Por eso centré mis argumentos en demostrar la diferencia entre artesanía y arte; la obra de López Antay no se podía nombrar con un término desvalorizado y despectivo, sino con uno que demostrara sus valores frente al mundo del arte, es decir arte popular.

26 Stastny, Op.Cit. p.39.

27 Lauer, 1982: p.10.

28 Maltese, 1984: p.8.

29 Lauer, 1982: p.19. 
Pero la producción del arte popular ha cambiado con y desde López Antay en adelante, en el momento que comenzó a firmar sus retablos. El hecho de que su producción se separara poco a poco del anonimato, rompe una de las condiciones atribuidas tradicionalmente a la artesanía. La individualidad creadora, antes sólo característica del arte informado, aparece en la obra del artista popular y lo separa de la producción artesanal.

Otro tema por examinar es que, a partir del maestro ayacuchano, la producción ya no se centra en ciudades de provincias sino en la capital, lugar de todas las denominaciones y los cambios. Muchos artistas populares han abierto talleres en Lima para llegar a un mercado más dinámico y otros ya no pasan por Lima sino que llegan de su provincia directamente a las ferias europeas.

\section{6.- La opinión de Pablo Macera.}

Ante las objeciones de los artistas de la Aspap, que consideraban el arte de López Antay como mera artesanía, Macera ${ }^{30}$ considera el retablo como una "decisiva invención plástica" ${ }^{31}$ y teniendo en cuenta la variedad de temas y formas concluye: "La inventiva es aquí inagotable"32. Además, "algunos de estos retablos evolucionan con rapidez apartándose de sus modelos europeos" 33 . "El Sanmarkos ha cambiado profundamente en el curso de los 30 años (técnicas, formas, temas, objetivos y clientelas"34.

La composición horizontal del retablo es una creación única. El hecho curioso de que en la parte superior aparezcan "dos evangelistas y a veces tres, pero nunca cuatro" 35 , puede significar la interpretación personal hecha por el artista de la doctrina oficial que, además, se acomoda a sus necesidades expresivas. Ninguno de los evangelistas está asociado a sus animales simbólicos. Alguna vez se representa a San Juan evangelista con el símbolo del León, atribuido tradicionalmente a San Marcos. ${ }^{36}$ La alusión al Espíritu Santo, sustituido por el cóndor, es interesante y tiene las trazas de una referencia disimulada, que necesita comprobarse. En cambio la fiesta de la herranza "No es un trasplante español", pues según Macera, "las fiestas de marcación existían no solo entre los incas sino también en otras sociedades prehispánicas". ${ }^{37}$

En relación al tópico de "la mala influencia" de los indigenistas capitalinos sobre la producción popular, Macera es bien claro al explicar que "En la ciudad de Ayacucho (...) los artesanos venían a menos, sustituidos por mercadería industrial traída desde la costa"38, por esta razón el Sanmarkos estaba amenazado de extinción. Por las sugerencias de los artistas indigenistas capitalinos, López Antay acoge ciertas ideas que le dan "la posibilidad de utilizar el retablo como una forma de representación plástica de su propio mundo. Él -y otros después- diversificaron el retablo"39.

En su "deformación” o trasformación -dice Macera- tiene más importancia "el nuevo tipo de comercialización que vincula al artesano con los grandes mercados urbanos del

30 Macera, 1982.

31 Macera, 2009: p.183.

32 Ibid, p.183.

33 Loc.cit.

34 Loc.cit.

35 Loc.cit.

36 Pintura “Los Santos Juanes protectores de la vida pastoril”, temple sobre tela enyesada, siglo XIX, Colección Mari Solari.

37 Macera, 2009: p, 183.

38 Ibid,. p. 184.

39 Ibid,. p. 184. 
exterior" ${ }^{40}$ y requiere una producción masiva que traduce muchos motivos en clave kitsch. Para Macera no puede haber un juicio definitivo sobre la evolución del retablo y a pesar de las deformaciones y exageraciones "no podemos negar que esos mismos extravíos nos están demostrando el poder de un arte todavía en plena búsqueda" ${ }^{2}$. Recordemos que este texto se publicó por primera vez en $1982^{42}$.

\section{7.- Musealización, aportes bibliográficos y preguntas ambiguas.}

Es indudable que la musealización de los objetos de arte popular ha contribuido a la conservación y difusión de sus prototipos y, a pesar de haber perdido su carácter religioso o mítico, es innegable que al entrar al museo han adquirido una nueva "aura"43 convirtiéndose en objetos ejemplares. Para preservar los objetos culturales, desafortunadamente no queda otra solución que "desraizarlos" de su estado natural para reinterpretarlos gracias a la historia y la museología de acuerdo al pensamiento de la época. Así, cada generación da sentido al mundo de sus objetos: de la realidad vivencial de los pueblos se pasa a la comprensión erudita y a la generalización abstracta que, al final, asume la palabra cultura. Esa labor la han cumplido los pocos museos existentes en el Perú dedicados al arte popular.

La investigación sobre el arte popular peruano cobró un nuevo impulso luego del premio a don Joaquín López Antay. Pero una empresa encomiable que no puede soslayarse, es la programación de exposiciones y ediciones sobre arte popular emprendidas por el Instituto Cultural Peruano Norteamericano y la Universidad Ricardo Palma. Desde la muestra "Del Sanmarkos al retablo ayacuchano" (2003) hasta "¿Arte popular? Tradiciones sin tiempo" (2014-15), han sido once exposiciones con sus respectivos catálogos que tuvieron miles de visitantes y material informativo profusamente ilustrado, hoy distribuido en las más importantes bibliotecas del Perú; han servido, también, para que los artistas populares actuales tengan presente la tradición, se inspiren en ella o produzcan las variaciones que su libre creatividad les dicte.

Es interesante ver en el último libro de la serie "¿Arte popular? Tradiciones sin tiempo", el sentido adquirido por los signos de interrogación que encierra el título. El autor, John Alfredo Davis, uno de los presentadores de la edición y curador de la muestra, sutilmente pone en duda el uso de la denominación "arte popular". Por otro lado, adjudica a ese arte una tradición sin tiempo, dando a entender que sus prototipos son inamovibles, o que el reloj de la creatividad se ha detenido y no hay posibilidad de evolución. Desde que en su momento se hizo la diferenciación entre arte y artesanía, el hecho de poner en duda el término es irrelevante, pues son admisibles también las denominaciones "arte tradicional" o "arte del pueblo". Dice el autor: "Sin embargo, en el Perú, "artesanía” es actualmente sinónimo de "arte popular (...) término bajo el cual se han agrupado todas la expresiones materiales de los pueblos del Perú" 44 . Le preocupa al autor esta indefinición "que ha puesto en riesgo las artes tradicionales y por tanto las expresiones materiales de las culturas de los pueblos del Perú”. Pero una simple definición no pone en peligro el arte popular, si es genuino; a donde apunta Davis es a "desambiguar"45 el término "arte popular", pero su propuesta oscila entre artesanía y arte tradicional, sin llegar a aclararse del todo. Para esto da un rodeo por la historia del artesanado y de los gremios desde el virreinato, pasando por el siglo XIX y XX, donde junta zapateros, herreros, aparejadores, hojalateros, plateros,

40 Ibid,. p. 185.

41 Ibid,. p. 185.

42 Separata del Boletín de Lima, № 19-20, Lima, 1982.

43 Benjamin, 1966. p. 24.

44 Davis, 2014-15: p. 78.

45 "Desambiguar", neologismo empleado por Davis que quiere significar lo contrario de ambiguo: definido, preciso, específico. 
sastres con colchoneros, caldereros, botoneros, pasamaneros, etc., que si bien es útil para comprender el paso de la artesanía hacia la industrialización en el Perú, en realidad no tiene que ver con el arte popular andino ni con la polémica generada. ${ }^{46}$

Pero en el empeñoso trabajo de "desambiguar", definir y clasificar los objetos artísticos populares, Davis se encuentra ante el problema de buscar un sitio para el arte de la selva peruana. ¿Dónde ponerlo? Davis dice: "El arte (...) Shipibo-Conibo no es popular pues, por un lado, los que realmente lo entienden son los miembros de la etnia" 47 . Los que no son del grupo "sólo comprenden debido a un manejo de información o porque ven en éste cualidades del "nuevo arte" o el "arte artístico", según Ortega" 48 En mi opinión a los miembros de la etnia no les interesa saber si lo que hacen es arte etnográfico o arte popular y los de afuera, turistas y público en general, se ven atraídos por sus cualidades estéticas y tampoco están interesados en clasificarlos. Quienes se interesan en las clasificaciones son los estudiosos, los marchands y la crítica. Aún así, Davis ordenó el sentido de la exposición en cuatro grupos:

Arte etnográfico, es la "producción realizada exclusivamente para uso personal o comunal, la que es portadora también de una carga simbólica compleja y original" 49 . Y concluye: "Toda expresión propia de una etnia es arte etnográfico, sea producida en zona urbana o rural".

Esta aseveración drástica y excluyente no tiene en cuenta que si la actividad se realiza en zona urbana o rural ya sale del grupo íntimo y familiar y pasa al más amplio de lo popular y del mercado. ¿O acaso los mates de Cochas no han surgido de un pequeño pueblo del Mantaro y se han expandido por toda la región? Además, el hecho de que hayan sido elaborados para su uso personal no les resta lo popular y sus valores artísticos y estéticos.

Arte tradicional rural, llama Davis a "las manifestaciones plásticas producidas por residentes del ámbito rural quienes no son identificados como integrantes de una etnia. El desarrollo de esta tradición plástica está generalmente sujeto a los períodos de siembra y cosecha del calendario agrícola. La producción, desarrollo y comercialización de estos objetos suele ser realizada por los mismos artistas, ofreciendo sus obras en ferias locales a pobladores de las zonas próximas"

Arte tradicional urbano, "Las obras de arte tradicional urbano son producidas para diferentes públicos -rurales, internos o externos, o internacionales- y se adecúan a las nuevas exigencias del mercado" 51 . En mi opinión, si se adecúan a las "nuevas exigencias del mercado" y a la posibilidad de cambio, entonces la denominación "arte tradicional urbano" no es la adecuada. Prueba de ello son los ejemplos de gráfica urbana que pone Davis en las páginas 202 a la 205, y que, como sabemos, han surgido espontáneamente en la ciudad, fuera de toda tradición. La indefinición o ambiguiedad de lo que entiende por "arte tradicional urbano" hace que el autor ubique en esta sección tablas de Sarhua o cuadros "al estilo Sarhua”, cuando ya en la sección de arte etnográfico había incluido tres ejemplares del estilo primigenio de esta localidad ayacuchana, induciendo a confusión. Y por último:

Arte tradicional aplicado, definido por el autor como "Obras generadas como propuestas individuales del artista o diseñador, o en base a pedidos específicos de una clientela

\footnotetext{
46 Op. Cit. Pags. 81 a 87.

47 Op. Cit. p. 90.

48 Op. Cit. p. 90.

49 Op. Cit. p. 115

50 Op. Cit. p. 163.

51 Op. Cit. p. 201.
} 
conocedora de la calidad del taller de donde proceden”52. En esta sección incluye Davis a los artistas-coleccionistas actuales que toman diseños tradicionales, sean precolombinos como populares o también propios y encargan su ejecución a un artesano; también diseñadores de artesanía fina en plata, adornos, muebles, cerámica y tejidos para la venta en boutiques. Obviamente estos objetos están lejos de considerarse arte popular y sólo son artesanía fina, de muy buen acabado, basada en diseños tradicionales que han perdido su significación primigenia.

Es indudable que John Alfredo Davis es un gran conocedor del arte popular; nadie como él -entre los hombres de su generación- ha viajado por todo el Perú, ha visitado talleres, conocido las técnicas y las maneras de producción. También ha incursionado en la artesanía, reproduciendo objetos con gran fineza y respeto por los prototipos, instando a los maestros y artistas a seguir el buen camino de la tradición. Pero su cariño y dedicación al arte popular y su pasión por poner orden en ese mundo, lo inducen a redefinir inútilmente ciertos términos empañando su discurso con trazas de confusión y ambiguiedad. ${ }^{53}$

\section{8.- A modo de conclusión.}

La tarea de diferenciar la artesanía del arte fue necesaria en su momento para comprender por qué el Sanmarkos o retablo, reinterpretado por López Antay, debía ser considerado, con toda razón y validez, obra de arte popular. Los argumentos a favor de esta idea son hoy día mejor comprendidos que en su momento, es decir en 1975 . El retablo, aunque proviene de la tradición religiosa barroca virreinal, es mestizo y una reelaboración de los artistas ayacuchanos que deja ver la concepción del mundo andino, sus creencias y valores, tan genuinos como los occidentales.

Luego de esta distinción, aceptada como una convención, queda ver si la denominación "arte popular" es conveniente. En este sentido, la propuesta de Stastny es la más acertada; es decir, considerar como arte popular "todo lo que no pertenece a las artes oficiales de la iglesia y de las elites políticas y sociales de los grandes centros urbanos" 54 . Una vez establecida la diferencia entre la artesanía y el arte, es irrelevante usar otras denominaciones como "arte tradicional", "arte del pueblo", porque se ha salvado la naturaleza de lo artístico del arte popular negada en su momento por los artistas informados. La propuesta de Stastny tiene la ventaja de ser más clara y sencilla y encarar el asunto desde el punto de vista del binomio oficialismo/no oficialismo, traducible como tradición occidental/tradición autóctona.

El arte popular, antes anclado en la tradición, hoy día, gracias al desarrollo del mercado y de los medios de comunicación, ha ido evolucionando y se ha hecho eco del desarrollo de la sociedad contemporánea. Por un lado el aflorar de la individualidad del artista popular reflejada en el hecho de firmar sus obras; por otro, el surgimiento de creadores ejemplares (López Antay, Jesús Urbano Rojas, Florentino Jiménez Toma, Edilberto Jiménez), y por fin, el traslado de los centros de producción de la provincia a la capital, han operado cambios en la valorización de estos objetos, convertidos hoy en prototipos gracias al proceso de musealización.

52 Op.cit. p. 259.

53 "Toda artesanía no es arte y todo arte no es artesanía. Todo arte material involucra el proceso artesanal, el oficio" (sic.). Op. Cit. p. 91.

54 Stastny, 1979. p. 43. 


\section{Referencias bibliográficas}

Albizu, Edgardo

2000 Verdades del Arte. Serie Humanitas. Argentina: Editor Jorge Baudino.

Benjamín, Walter

1966 L'opera d'arte nell'epoca della sua riproducibilità tecnica. Torino-Italia: Editorial Einaudi editores.

\section{Castrillón Vizcarra, Alfonso}

1986 Museo peruano. Utopía y realidad. Lima: Editorial Universitaria, Universidad Ricardo Palma.

2001 ¿El ojo de la navaja o el filo de la tormenta?. Lima-Perú: Editorial Universitaria Universidad Ricardo Palma.

Davis, John Alfredo

2014-2015 "El Arte peruano tradicional y las artes aplicadas", En ¿Arte popular? Tradiciones sin tiempo. Lima-Perú: ICPNA-URP.
Macera, Pablo

1982 "Los retablos andinos y don Joaquín López Antay", Separata del Boletín de Lima. № 19, Enero 1982 y № 20, Marzo 1982.

2009 Trincheras $y$ fronteras del arte popular peruano, Lima-Perú: Fondo del Congreso del Perú, Miguel Pinto (Compilador).

Maltese, Corrado

1975-1984 Guida allo studio della storia dell'arte, Mursia, Milano, Italia.

Stastny Mosberg, Francisco

1979 "Dimensión histórica del Arte Popular". En Historia y Cultura $\mathrm{N}^{\circ} 12$, Revista del Museo Nacional de Historia. Lima

1980 "Arte Popular en el Perú. ¿De qué se trata?", en La Revista No 1 . Lima.

1981 Las Artes Populares en el Perú. Lima: Fundación del Banco Continental para el Fomento de la Educación y la Cultura.

Ugarte Eléspuru, Juan Manuel

1976 Suplemento Dominical de El Comercio, Lima, 4 de enero. 